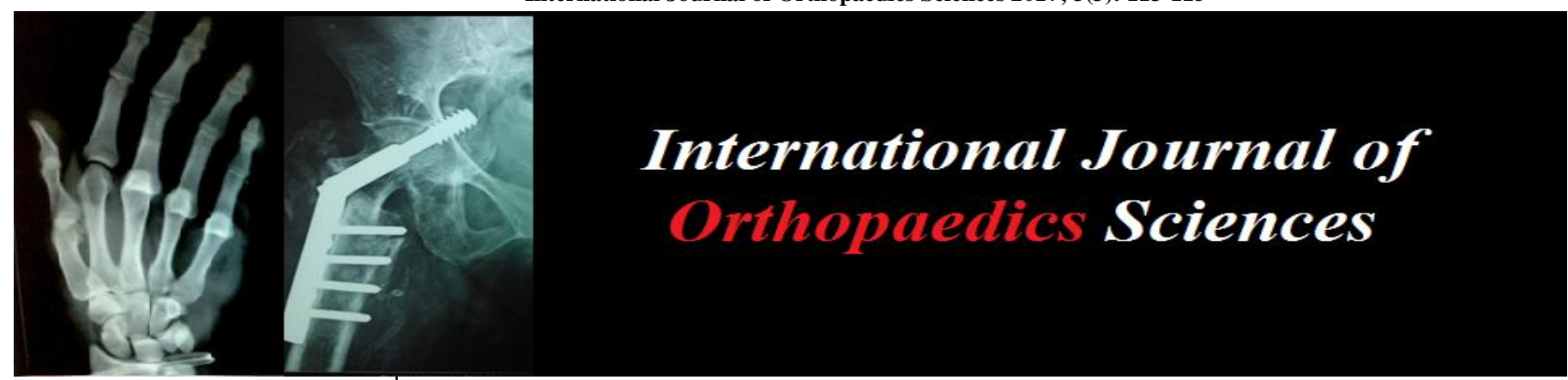

ISSN: $2395-1958$

IJOS 2017; 3(3): 113-115

(C) 2017 IJOS

www.orthopaper.com

Received: 10-05-2017

Accepted: 11-06-2017

Dr. Venkatesh Reddy

Professor, Dept. of Orthopedics,

PESIMSR, Kuppam, Andhra

Pradesh, India

Dr. Sai Krishna

Post Graduate, Dept. of

Orthopedics, PESIMSR,

Kuppam, Andhra Pradesh,

India.

Dr. Sameer Wooly

Assistant Professor, Dept. of Orthopedics, PESIMSR,

Kuppam, Andhra Pradesh, India

\section{A clinical profile of patients with distal tibia fractures attending tertiary care hospital}

\author{
Dr. Venkatesh Reddy, Dr. Sai Krishna and Dr. Sameer Wooly
}

DOI: http://dx.doi.org/10.22271/ortho.2017.v3.i3b.20

\section{Abstract}

Introduction: History of fractures and its knowledge dates back to Egyptian ummies of $2700 \mathrm{BC}$. For thousands of years the only option for the management of fracture was some form of external splintage. 5000 years ago, Egyptians used palm bark and Lenin bandages for management of fractures. Methodology: Appropriate and valid written consent was taken. The patient was taken for surgery after routine investigation and after obtaining fitness towards surgery. The investigations done were Hemoglobin percentage, fasting blood sugar, blood urea, serum creatinine, HIV, HbsAg and ECG. A dose of tetanus toxoid and antibiotic was given pre-operatively.

Results: Our study revealed the average age of patients with such injuries to be 40 years (21-60). In our study, the male predominance for such kind of injuries was high.

Conclusion: Closed fractures were more when compared to open fractures.

Keywords: distal tibia fractures, closed fractures, clinical profile

\section{Introduction}

Fractures have been recognized and treated as long as recorded history. History of fractures and its knowledge dates back to Egyptian ummies of 2700 BC. For thousands of years the only option for the management of fracture was some form of external splintage. 5000 years ago, Egyptians used palm bark and Lenin bandages for management of fractures. Clay and lime mixed with egg-white were used, but the material most commonly has been wood.

In 1897, first modern external fixator was developed by Dr. Clayton Park Hill of Denver. In 1906, Dr. Albit Lambotte designed a similar external fixator. Both are unilateral and allowed for 2 sets of screws to fix each bony fragment. In 1934, Dr. Roger Anderson developed a frame with transfixation pins. In 1938, Dr. Raowl Hoffman invented Hoffman fixator which was later modified by Dr. Vidal and Dr. Adrey by using multiplanar frame to increase the rigidity and was called Hoffman-Vidal system. However this frame was too rigid and static and thwarted union.

Distal metaphysical fracture of the tibia has been a challenging situation when mostly treated with Plaster of Paris casts, resulting in ankle and knee stiffness and prolonged immobilization. Internal fixation usually failed due to infection, inadequate skin coverage and avascular necrosis of the skin leading to slough. In a study of 84 patients that established the open reduction and internal fixation with screws and plate as the standard, the author with nine year follow-up reported $74 \%$ good functional results. Of the 84 fractures, 60 were secondary to low energy skiing injuries. $90 \%$ of the patients returned to their pre-injury occupations. 7 A series reported disastrous results when inadequate and unstable fixation was used to treat the distal tibial fractures. They had $36 \%$ of skin slough and $55 \%$ infection rates ${ }^{[1]}$. A retrospective review of 22 patients with distal third tibial fractures was treated with Titanium locking compression plate using minimally invasive technique. A total of $18 \%$ of good to excellent outcome was assessed using nAmerican Orthopedic Foot and Ankle Society Score ${ }^{[2]}$.

In a randomized, prospective comparison study of plate versus intramedullary nail fixation for distal tibial shaft fractures by Valliece HA et al concluded that open fractures had higher rates of infection, nonunion, and malunion. Intramedullary nailing was associated with more mal alignment versus plating. Fibula fixation may facilitate reduction of the tibia at the time of surgery ${ }^{[3]}$.
Assistant Professor, Dept. of Orthopedics, PESIMSR, Kuppam, Andhra Pradesh, India. 
In a study by Syed Abbas et al Nov 2009, assessment of the treatment outcome of closed extra-articular distal tibial fracture: IM nailing versus plating, concluded that plating technique has a satisfactory functional outcome, lower incidence of malunion and non-union ${ }^{[4]}$. A study by Shabbir et al, 2011 on minimal invasive plate osteosynthesis of the close fractures of distal tibia conclude that MIPO is an effective method of treatment for distal tibial fractures and is technically demanding but decreases surgical trauma to soft tissues ${ }^{[5]}$.

In a study by J.J.Guo et al Feb 2010, on comparing closed intramedullary nailing with percutaneous plating in the treatment of distal metaphyseal fractures of the tibia, 85 patients were randomized to operative stabilization either by a closed intramedullary nail (44) or by minimally invasive osteosynthesis with a compression plate (41), concluded that nailing has the advantage of a shorter operating and radiation time and easier removal of the implant ${ }^{[6]}$.

In a study by Vallier June 2008, on Radiographic and Clinical Comparison of Distal Tibial Shaft Fractures $(4-11 \mathrm{~cm}$ Proximal to the Plafond): Plating Versus Intramedullary Nailing concluded that Delayed union, malunion and secondary procedures were more frequent after nailing ${ }^{[7]}$.

In 2007, Kasper et al studied treatment of distal tibial fractures: plate versus nail. A retrospective outcome analysis of matched pairs of patients, there was no difference with regard to time to union, non-union, hardware failure or deep infections between ORIF and IM nailing. Study results suggest that control of alignment is difficult with IM nailing of distal tibial fractures. For optimal alignment consider the use of ORIF for closed and type-I open extraarticular fractures in the distal third of the tibia ${ }^{[8]}$.

\section{Methodology}

All the patients were explained and motivated about the cosmetic problems and difficulties in daily routines by the application of an external fixator. Appropriate and valid written consent was taken. The patient was taken for surgery after routine investigation and after obtaining fitness towards surgery. The investigations done were Hemoglobin percentage, fasting blood sugar, blood urea, serum creatinine, HIV, HbsAg and ECG. A dose of tetanus toxoid and antibiotic was given pre-operatively. Preparation of the part was done before the day of surgery. Instruments we rechecked and sterilized before hand.

\section{Inclusion Criteria}

- Age: Above 18 years upto 60 years of either sex

- Distal Tibial extra articular fractures

- Open fractures (Gustilo type-I, type-II and type-III)

\section{Exclusion criteria}

- Pathological fractures

- Old neglected fractures

- Old fractures with implant failure

On admission of the patient, a careful history was elicited from the patient and/or attainders to reveal the mechanism of injury and the severity of the trauma. The patients were then assessed clinically to evaluate their general condition and the local injury. General condition was assessed with the vital signs and systemic examination. Methodical examination was done to rule out fractures at other sites.

\section{Results}

Table 1: Age distribution of patients studied

\begin{tabular}{|c|c|c|c|}
\hline Age in years & Plating group & Nailing group & Total \\
\hline $21-30$ & $7(22.6 \%)$ & $4(21.1 \%)$ & $11(22 \%)$ \\
\hline $31-40$ & $11(35.5 \%)$ & $7(36.8 \%)$ & $18(36 \%)$ \\
\hline $41-50$ & $10(32.3 \%)$ & $6(31.6 \%)$ & $16(32 \%)$ \\
\hline$>50$ & $3(9.7 \%)$ & $2(10.5 \%)$ & $5(10 \%)$ \\
\hline Total & $31(100 \%)$ & $19(100 \%)$ & $50(100 \%)$ \\
\hline Mean \pm SD & $39.87 \pm 9.89$ & $40.00 \pm 9.36$ & $39.92 \pm 9.59$ \\
\hline
\end{tabular}

$\mathrm{P}=0.964$, Not significant, student $\mathrm{t}$ test

Table 2: Comparison of Mode of injury in two groups studied

\begin{tabular}{|c|c|c|c|}
\hline Mode of injury & Plating Group & Nailing Group & Total \\
\hline Fall & $2(6.5 \%)$ & $1(5.3 \%)$ & $3(6 \%)$ \\
\hline RTA & $29(93.5 \%)$ & $18(94.7 \%)$ & $47(94 \%)$ \\
\hline Total & $31(100 \%)$ & $19(100 \%)$ & $50(100 \%)$ \\
\hline
\end{tabular}

$\mathrm{P}=1.000$, Not significant, Fisher Exact test

Table 3: Comparison of Side involved in two groups studied

\begin{tabular}{|c|c|c|c|}
\hline Side & Plating Group & Nailing Group & Total \\
\hline Left & $8(25.8 \%)$ & $9(47.4 \%)$ & $17(34 \%)$ \\
\hline Right & $23(74.2 \%)$ & $10(52.6 \%)$ & $33(66 \%)$ \\
\hline Total & $31(100 \%)$ & $19(100 \%)$ & $50(100 \%)$ \\
\hline
\end{tabular}

$\mathrm{P}=0.118$, Not Significant, Chi-Square test

Table 4: Comparison of Open/ close procedure in two groups studied

\begin{tabular}{|c|c|c|c|}
\hline Open /Closed & Plating Group & Nailing Group & Total \\
\hline Closed & $26(83.9 \%)$ & $16(84.2 \%)$ & $42(84 \%)$ \\
\hline Open & $5(16.1 \%)$ & $3(15.8 \%)$ & $8(16 \%)$ \\
\hline Total & $31(100 \%)$ & $19(100 \%)$ & $50(100 \%)$ \\
\hline
\end{tabular}

$\mathrm{P}=1.000$, Not Significant, Chi-Square test

Table 5: Comparison of Fracture type in two groups studied

\begin{tabular}{|c|c|c|c|}
\hline Fracture type & Plating Group & Nailing Group & Total \\
\hline Nil & $26(83.9 \%)$ & $16(84.2 \%)$ & $42(84 \%)$ \\
\hline Type 1 & $0(0 \%)$ & $3(15.8 \%)$ & $3(6 \%)$ \\
\hline Type 2 & $3(9.7 \%)$ & $0(0 \%)$ & $3(6 \%)$ \\
\hline Type 3 & $2(6.5 \%)$ & $0(0 \%)$ & $2(4 \%)$ \\
\hline Total & $31(100 \%)$ & $19(100 \%)$ & $50(100 \%)$ \\
\hline
\end{tabular}

$\mathrm{P}=0.044+$, Significant, Fisher Exact test

\section{Discussion}

Our study revealed the average age of patients with such injuries to be 40 years (21-60). It is comparable to a study on similar fractures conducted by below authors.

Table 6

\begin{tabular}{|c|c|c|c|}
\hline Study & Minimum age & Maximum age & Average \\
\hline & (years) & (years) & \\
\hline TT Guo et al. ${ }^{[9]}$ & 23 & 70 & 42 \\
\hline C Mauffry et al. ${ }^{[10]}$ & 23 & 70 & 46 \\
\hline Present study & 21 & 60 & 40 \\
\hline
\end{tabular}

\section{Sex distribution}

In our study, the male predominance for such kind of injuries was high. $84 \%$ compared to other studies due to the fact that male dominance over females in travelling, occupational injuries etc. in India.

\section{Table 7}

\begin{tabular}{|c|c|c|}
\hline Study & Male percentage & Female percentage \\
\hline TT Guo et al. ${ }^{[9]}$ & 50 & 35 \\
\hline C Mauffry et al. ${ }^{[10]}$ & 66 & 34 \\
\hline Present study & 84 & 16 \\
\hline
\end{tabular}




\section{Clinical type}

In our study, closed fractures were more when compared to open fractures $(84 \%)$.

Table 8

\begin{tabular}{|c|c|c|}
\hline Study & Open \# \% & Closed \# \% \\
\hline Ajay Krishnan et al & 40 & 60 \\
\hline Present study & 16 & 84 \\
\hline
\end{tabular}

\section{Pattern (\%)}

We had a higher percentage of A2 fractures when compared to other studies where Kasper et al had $50 \%$ of A1 type fractures and Ajay Krishnan et al had $83 \%$ of A1 type fractures.

Table 9

\begin{tabular}{|c|c|c|c|}
\hline Study & A1 & A2 & A3 \\
\hline Kasper W et al. ${ }^{[8]}$ & $50 \%$ & $29 \%$ & $21 \%$ \\
\hline Ajay Krishnan et al. ${ }^{[11]}$ & $83 \%$ & $17 \%$ & \\
\hline Present study & $36 \%$ & $40 \%$ & $24 \%$ \\
\hline
\end{tabular}

\section{Conclusion}

- Our study revealed the average age of patients with such injuries to be 40 years

- A higher percentage of A2 fractures

\section{References}

1. Dillin L, Slabaugh P. Delayed wound healing, infection and non-union following open reduction and internal fixation of tibial plafond fractures. J Trauma. 1986; 26:1116-1119.

2. Ozakaya U, Parmaksizoglu AS, Gul M, Sokuou S, Kabukcuoglu Y. Minimally invasive treatment of distal tibial fractures with locking and non-locking plates. Foot Ankle Int. 2009; 30(12):1161-7.

3. Vallier Cureton. Patterson Randomized, prospective comparison of plate versus intramedullary nail fixation for distal tibia shaft fractures. J Orthop Trauma. 2011; 25(12):736-41.

4. Syed Abbas, Hajir Gharati. Mehdi-Assessment of the treatment outcome of closed extra-Articular distal tibia fracture: IM nailing vs plating, Medical Journal of the Islamic Republic of Iran.Vol. 23, No. 3, November, 2009

5. Shabbir, Shujaat, Zulfiqar, Kamran, Javed-Minimal invasive plate osteosynthesis of close fractures of distal tibia. J Ayub Med Coll Abbottabad. 2011; 23(2).

6. Guo JJ, Tang N, Yang HL, Tang TS. A prospective, randomized trial comparing closed intramedullary nailing with percutaneous plating in the treatment of distal metaphyseal fractures of the tibia Bone Joint Surg [Br]. 2010; 92-B:984-8.

7. Vallier Le, Toan T, Bedi Asheesh. Radiographic and Clinical Comparisons of Distal Tibia Shaft Fractures (4 to $11 \mathrm{~cm}$ Proximal to the Plafond): Plating Versus Intramedullary Nailing JOT. 2008; 22(5):307-311.

8. Kasper Janssen W, Jan Biert, Albert van Kampen. Treatment of distal tibial fractures: plate versus nail A retrospective outcome analysis of matched pairs of patientsInternational Orthopaedics (SICOT). 2007; 31:709-714. DOI 10.1007/s00264-006-0237-1

9. Guo JJ, Tang N, Yang HL, Tang TS. A prospective, randomized trial comparing closed intramedullary nailing with percutaneous plating in the treatment of distal metaphyseal fractures of the tibia. J Bone Joint Surg [Br].
2010; 92-B:984-988.

10. Mauffrey C, McGuinness Parsons N. A randomized pilot trial of locking plate fixation versus intramedullary nailing for extra-articular fractures of the distal tibia $\mathbf{J}$ Bone Joint Surg Br. 2012; 94-B:704-8.

11. Ajay Krishnan, Chetan Peshin, Dara Singh. Intramedullary nailing and plate osteosynthesis for fractures of the distal metaphyseal tibia and fibula Journal of Orthopaedic Surgery. 2009; 17(3):317-20. 